\title{
VIOLÊNCIA INTRAFAMILIAR: SUAS FORMAS E CONSEQUÊNCIAS
}

\section{ARTIGO DE REVISÃO}

LOPES, Líliam Dos Reis ${ }^{1}$

LOPES, Líliam Dos Reis. Violência intrafamiliar: suas formas e consequências. Revista Científica Multidisciplinar Núcleo do Conhecimento. Ano 06, Ed. 05, Vol. 05, pp. 161-173. Maio de 2021. ISSN: 2448-0959, Link de acesso: https://www.nucleodoconhecimento.com.br/psicologia/violencia-intrafamiliar, $\quad$ DOI: 10.32749/nucleodoconhecimento.com.br/psicologia/violencia-intrafamiliar

\section{RESUMO}

O vigente estudo aborda problemáticas que permeiam o tema violência doméstica e familiar, mais especificamente a violência intrafamiliar, referente às violações sofridas e praticadas entre aqueles que compõem o ambiente denominado lar. Compreendese a violência intrafamiliar como um evento cíclico, no qual ocorre o aprendizado por imitação, nos propiciando a compreensão de intergeracionalidade. Com objetivo de salientar a desigualdade de gênero, as consequências das violências sofridas por mulheres, assim como os danos sofridos pelos filhos e membros idosos de uma estrutura familiar com base na centralização do poder masculina, apresentando algumas definições de violência intrafamiliar, seus tipos e formas de manifestação social. O tipo de pesquisa selecionada foi revisão bibliográfica, com coleta de materiais pertinentes ao tema proposto. A coleta do material resultou em uma compreensão mais ampla da violência intrafamiliar consequente de um processo de aprendizagem que ultrapassam as gerações e assim perpetuando a prática da

1 Especialista em Avaliação Psicológica e Psicodiagnósticos pela Faculdade dos Vales Elvira Dayrell, FAVED; Especialista em Criminologia pela Faculdade dos Vales Elvira Dayrell, FAVED; Graduada em Psicologia pela Universidade da Amazônia, UNAMA.

RC: 84783

Disponível em: https://www.nucleodoconhecimento.com.br/psicologia/violencia-intrafamiliar 
violência. A pesquisa propicia considerar que a violência intrafamiliar é uma problemática que ultrapassa o ambiente familiar e afeta o indivíduo em sua totalidade, causando-lhe prejuízo social e pessoal.

Palavras-chave: Violência intrafamiliar, Psicologia da justiça, Ambiente Familiar.

\section{INTRODUÇÃO}

A violência intrafamiliar alcança uma parcela significativa da população mundial e repercute de forma negativa na vida dos indivíduos que a vivenciam, reproduzindo um comportamento violento e atinge a saúde física e psíquica dessas pessoas comprometendo as relações futuras. Configurando-se assim em um problema que requer atenção do poder público.

Observa-se que a violência intrafamiliar tem singularidades por ocorrer em um ambiente de intimidade, fator que contribui na distorção da compreensão dos eventos como sendo violação, isso acontece em decorrência dos vínculos existentes entre vítima e agressor, sendo necessário conhecimento mais profundo dos fatores geradores de cada comportamento.

O foco central desta pesquisa é, então, o de investigar e identificar as formas de violência intrafamiliar e as possíveis consequências apresentadas por cada membro familiar. A coleta do material bibliográfico ocorreu de maneira virtual a partir de consultas em plataformas virtuais como Google acadêmico, Scielo, Pepsic, Plataforma Brasil e bibliotecas virtuais.

A fim de salientar a relevância da pesquisa, ressalta-se que a violência intrafamiliar é identificada em todas as culturas, para que seja possível melhor aproveitamento do tema, a par da complexidade desse fenômeno em suas diversas manifestações, ele será problematizado sem ter a pretensão de esgotar a discussão sobre o assunto, abrindo margens para novas pesquisas sobre o assunto.

RC: 84783

Disponível em: https://www.nucleodoconhecimento.com.br/psicologia/violencia-intrafamiliar 


\section{DESENVOLVIMENTO}

\subsection{CONSIDERAÇÕES GERAIS SOBRE VIOLÊNCIA}

Ao se buscar na literatura o conceito mais amplo do significado da palavra violência é possível entender que esta está diretamente ligada as formas física, psicológica ou intelectual com o intuído de obrigar outro indivíduo a realizar algo contra seu querer, está atrelada ao constranger, incomodar, privar de liberdade, ao impedimento do outro de manifestar sua vontade, tendo como consequência viver fortemente ameaçado, espancado, humilhado, ferido ou mesmo resultando em morte (MODENA, 2016).

Em suma, significa usar a agressividade de forma intencional e excessiva para ameaçar, coagir, dominar outra pessoa negando-Ihe e violando um dos direitos básicos dos seres humanos que é a integridade física e psicológica. Essas violações acontecem das mais variadas formas e atinge a mulheres, crianças e idosos independente de nível social, credo ou raça (MODENA, 2016).

A violência é uma espécie de coação, consistente no emprego de força física ou arma de fogo para a obtenção de um resultado, contrário à livre vontade do sujeito passivo. A violência comporta modalidades diversas nos diferentes ramos do direito, na esfera penal é grande o número de crimes que se caracterizam pelo emprego da violência, o feminicídio é um crime que costuma utilizar variadas formas de violação até evoluir para as vias de fato. (BRASIL, 2003, 2006).

Com o advento da tecnologia e facilidade de acesso aos mais variados recursos bélicos que passou a ser comercializado de modo ilícito com fácil acesso, gerando o sentimento de incertezas e preocupações em decorrência de atentados, assassinatos, conflitos, dentre outros (BRASIL, 2003).

Morais (1993 p.79) considera que:

A violência é típica do ser humano. Ao longo de toda a história ela se tem feito presente. Ela sempre se originou de necessidades e

$\mathrm{RC}: 84783$

Disponível em: https://www.nucleodoconhecimento.com.br/psicologia/violencia-intrafamiliar 
interesses antagônicos geradores de um clima de disputa, de medição de forças. Todos percebem, porém, que jamais esta coisa do homem atingiu limites tão desumanos quanto agora e marcadamente nas cidades grandes.

Aos olhos da lei existe um tipo de violência que judicialmente requer punição, conhecida e intitulada como violência vermelha, aquela que exige energia do indivíduo, brutal e opressora, temos também a violência branca presente no cotidiano da sociedade, velada, tão devastadora quanto aquela, contudo cristalizada como normal pelo coletivo e assim pouco denunciada (BRASIL, 1940).

É claro que o crime pode ter várias causas, pode ocorrer por distúrbios orgânicos, como uma disfunção da glândula tireoide que transforma o mais pacato cidadão em um agressor de alta periculosidade; ou como uma doença mental (MORAIS, 1993 p.79)

Para Chauí o ato de violência vai além dos atos de brutalidade que envolvem força física e geram marcas visíveis, a natureza da violência estaria em essência ao ato de ultrapassar um limite ao qual gere consequências danosas a outrem, podendo ocorrer por meio de intimidações, coerções, terror, medo, manipulações, chamados de jogos psicológicos que desgastam psicologicamente a vítima, causando-lhes cansaço emocional e sensação de incapacidade em diversas áreas da vida.

Veja-se em Chauí (1998, p.34).

Etimologicamente, violência vem do vis, força, e significa: tudo que age usando a força para ir contra a natureza de algum ser (é desnaturar); Todo ato de força contra a espontaneidade, a vontade e a liberdade de alguém ( é coagir, constranger, torturar, brutalizar); Todo ato de violação da natureza de alguém ou de alguma coisa valorizada positivamente por uma sociedade ( é violar); Todo ato de transgressão contra aquelas coisas e ações que alguém ou uma sociedade define como justas e como um direito; Consequentemente, violência é um ato de brutalidade, sevícia e abuso físico e/ou psíquico contra alguém e caracteriza relações intersubjetivas e sociais pela opressão, intimidação, pelo medo e pelo terror.

Algumas formas de violências presentes na vida coletiva apresentam-se explícitas ou veladas pois, a convivência contínua com situações de violência marca a vida do indivíduo influenciando nas tomadas de decisão e interação deste no ambiente social

RC: 84783

Disponível em: https://www.nucleodoconhecimento.com.br/psicologia/violencia-intrafamiliar 
comunitário. Para melhor assimilação dos comportamentos resultantes da violência intrafamiliar, faz-se propício a compreensão das formas de violência presentes no ambiente familiar (CAPONI, 2007; DANTAS-BERGES, 2005).

\subsection{VIOLÊNCIA INTRAFAMILIAR}

A submissão feminina é um fator histórico que perpassa muitas gerações, a mulher ao longo dos tempos tem sido vítima de descriminação, seus direitos e liberdade são tolhidos tendo sua existência coisificada, posição esta resultante de uma discriminação sociocultural, alicerçado no machismo estrutural que se encontra imerso no contexto social (DAROSSI, 2009; SAFFIOTI, 1987, 2001).

O papel do homem em contrapartida é uma posição de destaque no núcleo social, alcançando patamares mais elevados, tanto no sentido econômico quanto político e essa posição de superioridade se estende à família, implementando assim celeiros de opressão, submissão e dominação do gênero masculino sobre o feminino (DAROSSI, 2009; SAFFIOTI, 1997).

Diante da concepção familiar patriarcal, onde predomina uma suposta superioridade masculina, o problema social, intitulado violência de gênero vem perdurando ao longo dos tempos, problemática silenciosa e protegida pelos códigos e costumes familiares, presente na maioria das moradias. Mesmo com a constante divulgação da Lei 11.340 no Brasil, ainda existem vítimas sofrendo opressão por desconhecer seus direitos e até mesmo identificar comportamentos classificados como violentos por parte do parceiro (BRASIL, 2006; DANTAS-BERGER, 2005; SAFFIOTI, 1997).

Todo e qualquer tipo de violação ou agressão dentro do âmbito familiar, seja física, psicológica ou socioeconômica compreende-se como violência intrafamiliar variando de intensidade e forma, todavia seus danos são profundos e algumas vezes letais. A complexidade das relações humanas conduz o Direito a redefinição no que tange à seguridade dos direitos fundamentais e no trato com os crimes enquadrados nesta categoria (BRASIL, 2002, 2006; DANTAS-BERGER, 2005).

$\mathrm{RC}: 84783$

Disponível em: https://www.nucleodoconhecimento.com.br/psicologia/violencia-intrafamiliar 
Nas últimas décadas muitas foram as tentativas de coibir essa prática, campanhas informativas, criação de leis protetivas, ressalta-se a 11.340 de 7 de agosto de 2006, também chamada de Lei Maria da Penha, que pode ser considerada uma das maiores conquistas feminista, considerando o nível de discriminação e opressão sofridas antes da instituição da Lei. Contudo ainda existe um longo caminho a ser percorrido no que diz respeito à segurança e integridade dentro dos lares, a violência está presente no seio das famílias e acomete principalmente mulheres e crianças, criando um círculo geracional de violência (BRASIL, 2016; CAVALCANTI, 2007).

A violência intrafamiliar pode vitimizar crianças e adolescentes materializa-se no espaço privado do lar, por pais, responsáveis ou membros familiares que subjugam a criança e adolescente como propriedade, fazem uso do poder familiar para exercer práticas de violência física, sexual, psicológica, patrimonial que resulta em negligência e violação de direitos (CHAVES, 1997).

Segundo Cardoso (1997 apud MENEZES, 2000), a convivência em ambientes de constante violência por parte dos pais pode ser um fator de perpetuação do comportamento agressivo nos filhos. Segundo esse o ciclo de violência é intergeracional, construindo uma subjetividade que naturaliza atos de violação e assim reproduz a violência quotidianamente, uma maneira disfuncional de vínculos afetivos, com base na repressão e opressão.

Para Cardoso (1997 apud MENEZES, 2000, p.128):

Sofrer violência na infância torna as pessoas inseguras, com baixa autoestima, com ausência de senso crítico sobre a violência e dificuldades de estabelecer relações positivas. Essas consequências repercutem na escolha que a mulher fará de seu futuro marido, bem como na sua reação frente à violência.

Traçar um panorama da violência doméstica requer estudo e análise profundos, pois a complexidade da situação requer um olhar atento às várias formas de violação que costumam ocorrer de modo cíclico, ou seja, caracteriza-se por fases que perpassam 
desde insultos verbais, humilhações, abuso de poder financeiro, terror psicológico, agressões físicas e até mesmo a morte (FONSECA, 2006; HERMANN, 2008).

As vítimas são coagidas a ponto de considerarem-se as culpadas pela violência, resultando em pessoas passivas incapazes de proferir qualquer atitude em própria defesa, facilitando e encorajando o comportamento do agressor que na certeza da impunidade segue seu ciclo violento (DANTAS-BERGER, 2005).

A violência doméstica como uma questão de saúde pública, que afeta negativamente a integridade física e emocional da vítima, seu senso de segurança, configurada por círculo vicioso de frequentes idas aos serviços de saúde e o consequente aumento com os gastos neste âmbito (GROSSI, 1996).

Outra forma de violação intrafamiliar é contra o idoso nas famílias que tem essa configuração, costuma ser velada, assim como as demais já discutidas, isso em decorrência da crença social de não invasão das normas e regras estabelecidas por cada grupo familiar. Porém salienta-se em Rosenvald (2017) que a justiça poderá intervir na organização familiar sempre que esta for contrária aos direitos da pessoa.

Para Berger (2003), a caracterização da velhice está relacionada à etapa final da vida no qual perpassam anseios, medos, dúvidas, também considerada a etapa da vida que traz sabedoria e maturidade, ressalta-se também o preconceito existente devido as limitações características dessa etapa da vida, a discriminação contra a pessoa idosa consiste em estereotipar as mesmas como sendo ultrapassada, isolada, incapaz de realizar atividades quotidianas. Para a autora essa compreensão encontra-se ultrapassada, haja vista que os hábitos e costumes sociais modificaram contribuindo para uma qualidade e longevidade maior.

O estereótipo do envelhecimento associado a inutilidade humana pode resultar em violações de direitos, ocorrendo com maior frequência no ambiente intrafamiliar. É comum que a pessoa idosa conviva na residência de um dos filhos, isso em 
decorrência das limitações físicas do idoso, condições de vulnerabilidade que exigem supervisão (BERGER, 2003).

A violência doméstica ocorre de diferentes maneiras e em todas as suas esferas causa graves danos, dentre suas manifestações temos a violência física, psicológica e socioeconômica, podendo ocorrer de modo simultâneo ou isolado com os membros do grupo familiar (BRASIL, 2006, 2016; MODENA, 2016).

Violência Física: quando ocorrem agressões intencionais ou impulsivas, causando prejuízos físicos a pessoa, podendo chegar a óbito. A violência física acontece tanto pelo uso das mãos ou instrumentos, alguns com a intenção de manipular a perícia, dificultando ainda mais a denúncia e a aplicação de medidas punitivas (BRASIL, 2006; MODENA, 2016).

A violência física é um delito tipificado pelo Código Penal brasileiro, no título que descreve os crimes contra a pessoa, o artigo 129 , $§ 10$ prevê aumento da pena para crimes que envolvem violência doméstica, isso inclui que, em todos os casos havendo lesão corporal, sendo leve, grave ou seguida de óbito (BRASIL, 1940).

Entende-se por violência psicológica qualquer conduta que cause danos emocionais ao indivíduo, que the diminua a autoestima, com o intuito de prejudicar, comprometendo o desenvolvimento pleno, oprimindo ou controlando as ações, comportamentos por intermédio de ameaças, constrangimentos, humilhação, ironia, manipulação, ridicularização, insultos e quaisquer das formas de agressão verbal, esse tipo de violência pode ocorrer com qualquer integrante do grupo familiar quando as relações são assimétricas e disfuncionais (BRASIL, 2006; MODENA, 2016; ROSENVALD, 2017).

A violência psicológica é sutil, pouco perceptível pelas demais pessoas, porém com fortes consequências para a vítima, que acumula medos, inseguranças e crenças distorcidas da realidade, causando prejuízo ao desenvolvimento social e pessoal, por

$\mathrm{RC}: 84783$

Disponível em: https://www.nucleodoconhecimento.com.br/psicologia/violencia-intrafamiliar 
não deixar marcas aparentes é mais difícil de ser combatida, mulheres, crianças e adolescentes são suas maiores vítimas (CAPONI, 2007).

A violência socioeconômica acomete principalmente mulheres, comumente detectada dentro dos lares, configura-se como a condição em que vítima é obrigada a viver com o agressor pela relação de dependência financeira, sofrendo coação, retenção de documentação pessoal dentre outros. Os casos de dependência financeira costumam ser acompanhados de alto nível de violação psicológica, quando a vítima se encontra com a autoestima baixa, pouca esperança e perspectiva de mudança, esse quadro costuma apresentar como característica principal a assimetria de gênero, fenômeno resulta da cultura patriarcal (BRASIL, 2006; DAROSSI, 2009).

O artigo $7^{\circ}$, inciso IV da Lei no 11.340/06, define a violência patrimonial como qualquer conduta que configure retenção, subtração, destruição parcial ou total de seus objetos, instrumentos de trabalho, documentos pessoais, bens, valores e direitos ou recursos econômicos, incluindo os destinatários a satisfazer suas necessidades, dentre os quais podemos mencionar quase todos os tipos penais previstos no Título II, do Código Penal, que descreve os crimes contra o patrimônio, tais como estelionato (art.171); dano (art.163), furto (art.155); roubo (art.157); extorsão (art. 158); apropriação indébita (art.168) e outros, desde que praticados contra a mulher, por pessoa com quem a vítima tenha relação de convivência, afetiva ou familiar, independentemente de coabitação (BRASIL, 1940, 2006; HERMANN, 2008).

Leda Maria Hermann (2008, p. 114) considera que:

A violência patrimonial é forma de manipulação para subtração da liberdade à mulher vitimada. Consiste na negação peremptória do agressor em entregar à vítima seus bens, valores, pertences e documentos, especialmente quando esta toma a iniciativa de romper a relação violenta, como forma de vingança ou até como subterfúgio para obrigá-la a permanecer no relacionamento do qual pretende se retirar.

Nesse tópico faz-se necessário ressaltar que a caracterização de violência sexual é mais ampla e apresenta muito mais manifestações do que costumamos discutir nos

RC: 84783

Disponível em: https://www.nucleodoconhecimento.com.br/psicologia/violencia-intrafamiliar 
ambientes sociais. De acordo com a Lei, 11.340 a violência doméstica ocorrida no ambiente familiar é caracterizada como qualquer comportamento que constranja, obrigue ou intimide a vítima, violando sua liberdade sexual e a autonomia da mulher com seu corpo (BRASIL, 2002, 2006).

A configuração do matrimônio é um fator que naturaliza o abuso sexual entre cônjuges, pois o homem alega ter direitos sobre o corpo feminino constituído pelo enlace. Faz-se necessário salientar que o corpo é propriedade privada e inviolável do indivíduo, pertencendo exclusivamente a si próprio, precisa então o ato sexual ser consentido por ambas as partes, sem ameaças ou coerções para não se caracterizar como abuso (BRASIL, 2006; DUTRA-BERGER, 2005).

Dantas-Berger (2005) a violência conjugal ocorre com frequência nas famílias onde existe assimetria de poder, em que geralmente o homem detentor do recurso financeiro passa a inferiorizar a mulher que ocupa o papel de cuidadora do lar, essa assimetria intensifica o comportamento agressivo do homem levando a mulher a ocupar uma condição passiva em decorrência da dependência financeira.

A violência conjugal também aparece em famílias onde a mulher tem poder financeiro similar ou maior que o do parceiro, isso ocorre devido a subjugação da condição feminina, pois este homem carrega intrinsecamente a crença de que a condição feminina é inferior à condição masculina (DANTAS-BERGER, 2005).

Outra forma de violência sexual intrafamiliar é o abuso contra crianças e adolescentes a Lei 8.069 tem como característica principal o envolvimento de uma pessoa adulta com uma criança, compreende-se que nesse envolvimento existe uma assimetria de poder, fazendo do adulto alguém com persuasão, poder aquisitivo ou mesmo força física, capazes de manipular ou intimidar a criança a comportar-se de modo passivo (CHAVES, 1990).

Esse tipo de violência deixa danos nas vítimas, tirando-lhes a confiança nas demais pessoas, quando adultas encontram dificuldade em estabelecer relacionamentos

RC: 84783

Disponível em: https://www.nucleodoconhecimento.com.br/psicologia/violencia-intrafamiliar 
íntimos saudáveis, costumam apresentar medo ou repulsa aos parceiros sem compreender os motivos. As principais consequências apresentadas são os comportamentos de insensibilidade, embotamento afetivo, nível reduzido de apatia (CAPONI, 2007; FONSECA, 2006; MILLER, 1999; SAFFIOTI, 2001).

A violência em todas as suas formas de manifestação acarreta danos não somente no que se refere às condições físicas das pessoas vitimadas, causa prejuízos no desenvolvimento e no equilíbrio moral, social/afetivo e psíquico levando a quadros depressivos ou até mesmo a morte. A vítima de violência intrafamiliar vivencia o desamparo no ambiente que julga mais seguro pelos laços afetivos e consanguíneos, essa ruptura de confiança pode causar desconfiança e reduzir as chances de estabelecer relacionamentos afetivos saudáveis (APA, 2006; CAPONI, 2007; MILLER, 1999).

\subsection{CONSEQUÊNCIAS DA VIOLÊNCIA INTRAFAMILIAR}

O fenômeno violência doméstica está presente no contexto familiar desde os primórdios da vida em sociedade, contudo a hostilidade com que muitas famílias convivem diariamente não pode ser vista com naturalidade, trata-se de um ciclo de violência que segundo a literatura existente se reproduz na geração seguinte (DANTAS-BERGER, 2005).

Essa realidade afeta não somente as mulheres, mas os filhos que presenciam e são vítimas da violência, crescendo e construindo sua subjetividade imersa em um cenário degradante com os direitos violados por aqueles que 0 deveriam proteger, consequentemente esse será o referencial de vínculo familiar que fará parte da vida adulta (FONSECA, 2006; MILLER, 1999).

O exercício da parentalidade é fortemente marcado pelas memórias afetivas da família à qual pertence uma pessoa, estabelecer uma parentalidade e conjugalidade equilibrada e saudável, pode representar um dos maiores desafios a ser enfrentado por vítimas do crime de violência intrafamiliar (FONSECA, 2006; MILLER, 1999).

RC: 84783

Disponível em: https://www.nucleodoconhecimento.com.br/psicologia/violencia-intrafamiliar 
Segundo Fiorelli e Mangini (2014), afirmam que:

\begin{abstract}
A violência praticada entre os cônjuges transmite aos filhos uma aprendizagem geral sobre os métodos de exercê-la e desenvolve uma percepção de que tais comportamentos são válidos como forma de relacionamento interpessoal - afinal, não possuem outras referências. Por assimilação dos comportamentos dos modelos, serão por eles internalizados e praticarão, no futuro, a violência que aprenderam com os pais.
\end{abstract}

Neste sentido, crianças e adolescente que sofreram abusos físicos e psicológicos por familiares e/ou cuidadores possuem tendências a reproduzir esse tipo de comportamento na fase adulta, essas pessoas são propensas a bater em seus filhos, humilhá-los ou mesmo desenvolver comportamento violento em suas relações cotidianas (FONSECA, 2006; MILLER, 1999).

A família é o primeiro meio social com que a crianças tem contato, sendo esta por sua vez sua preferência, seu modelo a ser seguido e reproduzido, na busca de ser amada e aceita nesse meio de modo que todas as agressões sofridas nesse período comprometem gravemente a imagem que crianças e adolescentes possuem de si mesmos, tornando-os inseguros, com baixa autoestima, não críticos e em muitas vezes incapazes de romper o ciclo de violência (FIORELLI e MANGINI, 2014; FONSECA, 2006; MILER, 1999).

Diante da compreensão de violência intergeracional, faz-se necessário refletir que a violência contra a pessoa idosa resulta do ciclo de violência iniciado na infância, na família violenta e disfuncional os integrantes do grupo alternam o papel de vítima e agressor (GROSSI, 1996; KRUG, 2002).

\title{
3. CONSIDERAÇÕES FINAIS
}

É possível inferir que homens adultos com comportamento agressivo sofreram ou presenciaram atos de violência na infância, realidade presente em muitas famílias ao redor do mundo, propiciando característica intergeracional a violência.

RC: 84783

Disponível em: https://www.nucleodoconhecimento.com.br/psicologia/violencia-intrafamiliar 
A desigualdade socioeconômica de gênero é uma realidade que repercute na manutenção da violência intrafamiliar, pois a assimetria entre os cônjuges resulta em maior nível de violência, que por sua vez afeta diretamente a prole do casal assim como os idosos que compõem a estrutura familiar.

A violência intrafamiliar comporta em sua estrutura uma diversidade de formas de violação, é importante compreender que essa dinâmica sofre mudanças e até inversão de papéis vítima e agressor. A violência conjugal pode estender-se para violência infantil, a violência parental de hoje futuramente pode converter-se em violação contra o idoso.

O estudo realizado conduz a compreensão de um evento multifatorial, ocasionado por questões sociais não solucionadas pelas políticas públicas existentes. Toda forma de violência provém de uma assimetria de poder, que pode ser financeiro, intelectual ou físico. Salienta-se a necessidade de implementação de políticas públicas que se voltem para o rompimento desse ciclo, compreender a violência intrafamiliar como um problema social que anualmente gera despesas públicas e que uma das possíveis formas de avanço seja o da educação para a não violência.

\section{REFERÊNCIAS BIBLIOGRÁFICAS}

APA, American Psychological Association. Dictionary of Psychology. Washington, D.C.: APA. 2006.

BRASIL. Presidência da República. Decreto-Lei 2.848, de 07 de dezembro de 1940. Código Penal. Diário Oficial da União, Rio de Janeiro, 31 dez. 1940.

Decreto n. 4.377, de 13 de setembro de 2002. Promulga a Convenção sobre a Eliminação de Todas as Formas de Discriminação contra a Mulher, de 1979, e revoga o Decreto no 89.460, de 20 de março de 1984. Disponível em: http://www.planalto.gov.br/ccivil_03/decreto/2002/D4377.htm. Acesso em: 26 jun. 2020.

RC: 84783

Disponível em: https://www.nucleodoconhecimento.com.br/psicologia/violencia-intrafamiliar 
Lei n. 10.826, de 22 de dezembro de 2003. Dispõe sobre registro, posse e comercialização de armas de fogo e munição, sobre o Sistema Nacional de Armas - Sinarm, define crimes e dá outras providências. Disponível em: http://www.planalto.gov.br/ccivil_03/leis/2003/l10.826.htm. Acesso em: 26 jun. 2020.

Lei $\mathbf{n} . \mathbf{1 1 . 3 4 0}$, de 7 de agosto de 2006. Cria mecanismos para coibir a violência doméstica e familiar contra a mulher. Disponível em: http://www.planalto.gov.br/ccivil_03/_ato2004-2006/2006/lei//11340.htm. Acesso em: 26 jun. 2020.

Senado federal. Panorama da violência contra as mulheres no Brasil: indicadores nacionais e estaduais. Brasília: Senado Federal, 2016.

CAPONI et al. Violência Silenciosa: violência psicológica como condição da $\begin{array}{llll}\text { violência física } & \text { doméstica. } & & \\ & & \end{array}$ em:https://www.scielo.br/scielo.php?pid=S141432832007000100009\&script=sci_abstract\&tlng=pt Acesso em: 22 set. 2020

CARDOSO, N.M.B. Mulher e maus tratos. In: STREY, Marlene Neves (Org.). Mulher e estudos de gênero. São Leopoldo: Unisinos, 1997. Apud MENEZES, Ana Luiza Teixeira de. Mulheres: fruto de dominação e fruta para libertação! In: STREY Marlene Neves et al (Org.). Construções e perspectivas em gênero. São Leopoldo: Unisinos, 2000. p. 125-134

CAVALCANTI, Stela Valéria Soares de Farias. Violência Doméstica: análise da lei “Maria da Penha”, no 11.340/06. Salvador, BA: Edições PODIVM, 2007, p. 215

CHAUÍ, Marilena. Ética e violência. In: Colóquio interlocuções com Marilena Chauí. 1998, Londrina. mar. 1998/São Paulo. abr. 1998.

CHAVES, Antonio. Comentários ao Estatuto da Criança e do Adolescente 2. ed.São Paulo: LTr, 1997, Disponibilidade: Rede Virtual de Bibliotecas_Acesso em: 20 fevereiro 2021

$\mathrm{RC}: 84783$

Disponível em: https://www.nucleodoconhecimento.com.br/psicologia/violencia-intrafamiliar 
DANTAS-BERGER, Sonia Maria, \& GIFFIN, Karen. A violência nas relações de conjugalidade: invisibilidade e banalização da violência sexual? Cadernos de Saúde Pública[on-line]. 2005,vol. 21, n. 2, pp. 417-425. Disponível em:https://www.scielo.br/scielo.php?pid=S0102-

311X2005000200008\&script=sci_abstract\&tlng=pt.Acesso em: 20 fevereiro. 2021

DAROSSI et al. Violência Doméstica Contra a Mulher: Breve análise sobre a igualdade entre homens e mulheres no decorrer de situações históricas. Revista da Unifebe, 2009. Disponível em: < https://www.unifebe.edu.br/revistadaunifebe/2009/artigo030.pdf > Acesso em: 13 set. 2020

FIORELLI, J. O.; MANGINI, R. C. R. Psicologia Jurídica. São Paulo: Atlas, 2014.

FONSECA, Paula Martinez da; LUCAS, Taiane Nascimento Souza. Violência doméstica contra a mulher e suas consequências psicológicas. 2006. 21 f. Monografia (Curso de Graduação em Psicologia). Salvador/BA: Escola Bahiana de Medicina e Saúde Pública, 2006. Disponível em: http://newpsi.bvspsi.org.br/tcc/152.pdf. Acesso em: 13 fevereiro 2021.

GROSSI, Patrícia Krieger. Violência contra a mulher: implicações para os profissionais de saúde. In: Lopes, Meyer de Waldow. Gênero e Saúde. Porto Alegre: Artes Médicas, 1996. p. 133-149.

HERMANN, L. M. Maria da Penha, lei com nome de mulher: violência doméstica e familiar, considerações à Lei no 11.340/2006 comentada artigo por artigo. Campinas: Servanda, 2008.

KRUG et al. Relatório mundial sobre a violência e saúde. Organização Mundial da Saúde, Geneva: $2002 . \quad$ Disponível em:<http://www.academia.edu/7619294/Relat\%C3\%B3rio_mundial_sobre_viol\%C3 \%AAncia_e_sa\%C3\%BAde> Acesso em: 15 fevereiro. 2021

$\mathrm{RC}: 84783$

Disponível em: https://www.nucleodoconhecimento.com.br/psicologia/violencia-intrafamiliar 
MENEZES, Ana Luiza Teixeira. Mulheres: fruto de dominação e fruta para libertação! In: Marlene Neves Strey et al. (Org.). Construções e perspectivas em gênero. São Leopoldo: Unisinos, 2000. p. 125-134.

MILLER, Mary Susan. Feridas invisíveis: abuso não-físico contra mulheres. Tradução Denise Maria Bolanho. São Paulo: Summus, 1999.

MODENA. Conceitos e formas de violência [recurso eletrônico]: / org. Maura Regina Modena. - Caxias do Sul, RS: Educs, 2016

MORAIS, Regis de. O que é Violência Urbana. 10. ed. São Paulo: Brasiliense, 1993, p. 79.

ROSENVALD, Nelson e DE FARIAS, Cristiano Chaves. Curso de Direito Civil Famílias, Editora, Juspodivm, 2017.pgs. 42-44.

SAFFIOTI, Heleieth. Papéis sociais atribuídos às diferentes categorias de sexo. In: Heleieth Saffioti. O poder do macho. São Paulo: Moderna, 1987. p. 8-20.

Contribuições feministas para o estudo da violência de gênero. Cadernos Pagu, 2001. vol.16, pgs.115-136

Enviado: Abril, 2021.

Aprovado: Maio, 2021. 